\title{
THE ENIGMA OF VITRUVIAN RESONATING VASES AND THE RELEVANCE OF THE CONCEPT FOR TODAY
}

\author{
Rob Godman \\ The Music Centre \\ Faculty for the Creative and \\ Cultural Industries \\ University of Hertfordshire \\ United Kingdom \\ r.godman@herts.ac.uk
}

\begin{abstract}
The clarity of sound within Greek or Roman theatres (without any form of enhancement) will be impressive to any visitor. The seats arranged in curved rows around the circular orchestra form large horizontal reflecting surfaces. The paths of sound waves travel from the source (the actor or singer) to each of the listeners in a direct path (i.e. without obstruction or reflection). Vitruvius, however, claimed further enhancements could be made.

In theatres, also, are copper vases and these are placed in chambers under the rows of seats in accordance with mathematical reckoning. The Greeks call them Echeia. The differences of the sounds which arise are combined into musical symphonies...

... it becomes fuller, and reaches the audience with a richer and sweeter note.

Vitruvius, on Architecture, Book I, - on training of architects, Loeb

This paper explores the notion of intent and purpose behind the Vitruvian concept and also addresses an arguably more complex issue, that of a potential fusion between archaeology, science and art.
\end{abstract}

\section{INTRODUCTION}

\subsection{Vitruvius - the person}

Marco V. Pollio Vitruvius studied Greek philosophy and science around the $1^{\text {st }}$ Century BC. A practical exponent of his craft, he gained experience through his professional work and was the architect of at least one complete unit of buildings for Augustus in the reconstruction of
Rome. As an indication of his diverse talents, he also oversaw developments in the imperial artillery and military engines - making Vitruvius an important figure in his day.

In modern times, Vitruvius has been regarded primarily as an architect but his explorations of science and art in the widest sense should not be forgotten. The emphasis of books I-V is on architecture in the traditional sense of the word. The second of the five books contain information relating to Greek science demonstrating the background Vitruvius had during his studies and younger days. The inspiration of science was at one with art and literature (although this was not a philosophy specific to Vitruvius).

The science of the architect depends upon many disciplines and various apprenticeships which are carried out in the art.

Vitruvius, on Architecture, Book I - on training of architects, Loeb

\subsection{The Ten Books on Architecture}

De Architechura is a collection of ten books detailing his practical experience with traditional Greek theory of the time. Exact dates for the composition remain uncertain but it is believed to have been written around $27 \mathrm{BC}$ (towards the latter period of his life).

The complete treatise is detailed as follows:

Book 1: Architectural Principles

Book 2: Evolution of Building, Use of materials

Book 3: Ionic Temples

Book 4: Doric and Corinthian Temples 
Book 5: Public Buildings, Theatres (and music), Baths and Harbours

Book 6: Town and Country Houses

Book 7: Interior Decoration

Book 8: Water Supply

Book 9: Dials and Clocks

Book 10: Mechanical and Military Engineering

There are a number of surviving manuscripts that have been used to create the current published translations. These date from as early as the $8^{\text {th }}$ Century (London, British Museum). The text was rediscovered in the $15^{\text {th }}$ Century and has been studied by renaissance architects for a wider range of student to the current day. A number of translations of the text exist and are available in print. The three used for the purpose of this paper (Dover, Loeb and Cambridge University Press publications) are referenced in the bibliography.

\section{THEATRE DESIGN}

The design of a Roman theatre has much in common with its Greek counterpart. Before examining the differences, it is worth discussing terminology. It is a common mistake to name the semi-circular Greek and Roman theatres as amphitheatres. They are not! An amphitheatre is circular (think about the Coliseum in Rome) and a theatre is semi-circular (or at least close to it). The amphitheatre and theatre have vastly different uses.

The theatre of the Greeks was built on the slope of a hill, securing sufficient elevation for the back row from the naturally occurring landscape. The tiers were either cut directly into rock or if the land was soft an excavation was made in the hillside and lined with rows of benches. The steps were often faced with marble (as in the theatre of Dionysus at Athens). The theatre of the Romans and hence Vitruvius, was potentially a freestanding structure and therefore a much more complex design.

\section{GREEK/ROMAN MUSIC}

Before exploring the reasoning behind Vitruvius' concept of the resonating vases in Roman theatres it is important to have an understanding behind music principles of the time.
Harmony is an obscure and difficult musical science, but most difficult to those who are not acquainted with the Greek language; because it is necessary to use many Greek words to which there are none corresponding in Latin. I will therefore explain, to the best of my ability, the doctrine of Aristoxenus, and annex his diagram, and will so designate the place of each tone, that a person who studiously applies himself to the subject may very readily understand it.

Vitruvius, The Ten Books on Architecture, Book V, Dover

The systems as described by Aristoxenus and Pythagoras are different in terms of technical specification and philosophy. Vitruvius (as can be seen from above) follows the theory of Aristoxenus and it is this that the acoustic vases are based upon.

Aristoxenus lived around the $4^{\text {th }}$ Century BC and wrote a number of works on music and related disciplines (Elements of Harmonics still survives). He sets out a theory of scale structure and a method for analysis. His definition of interval is different to that of the Pythagoreans (which is based on ratio and proportion) in that he describes two pitches as being bounded or marked off by two notes of different pitch (Landels). A system is a construction of intervals, the smallest group of which is known as a tetrachord.

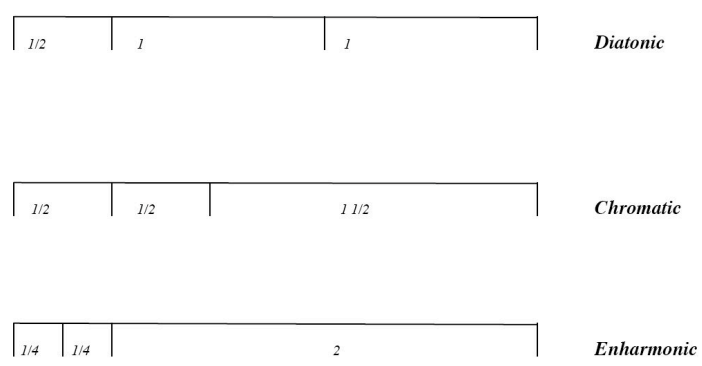

Figure 1

The groups of four pitches in each tetrachord are always surrounded by the interval of a fourth. Aristoxenus demonstrates three different types (diatonic, chromatic, enharmonic). He uses the term hemitonion to describe an interval of a semitone and more complex term of diesis for any interval smaller than a semitone (Landels). He does use mathematical ratios to assist with the concept of microtones but also spoke of them in terms of colour and other descriptive methods. 
To make more complex pitch systems it is a simple matter of placing one tetrachord on top of another (giving tetrachords based on cycles of fourths). This developed into the Greater Complex System giving a two-octave construction. This is the method that Vitruvius follows for the tuned vases.

\section{ACOUSTICS}

\subsection{Problems, vases...}

A greater understanding of acoustics can be identified as early as the beginning of the 5 th century BC (Dionysos at Athens and the theatre at Syracuse). Ironically, the shape of the theatres was not based on scientific understanding but rather by accident. A site on the side of a hill, sloping down at approximately 45 degrees gave a good acoustic result. Other portable solutions also helped the acoustic. Backdrops helped high-frequency reflections (provided by painted skins). It is believed the propagation of sound to the audience was aided by the megaphone effect of the masks worn by the actors.

Further developments in the shape of theatres are all thought to have been due to attempts at improving the acoustics. An increased length of the seating area (whilst maintaining overall proportion) brought more of the audience close to the stage and thus improved the acoustics, especially as less of the sound could escape at the sides of the orchestra. However, the direction in which the actors were facing became of greater importance, and the height of the stage building was increased and made of stone to provide more reflection from behind and improve the distribution of the sound. A few centuries later, and with the aid of his knowledge derived from Aristoxenus, Vitruvius was attempting to solve other acoustical problems still prevalent in Roman theatres.

The Pythagoreans formulated the modern science of acoustics in Greece in the 6th century BC. Aristoxenus examined the study of musical sounds further by going beyond the source and propagation of sound to consider issues of perception. The work concerning acoustics by Vitruvius is largely based on the writing s of Aristoxenus.

In theatres, also, are copper vases and these are placed in chambers under the rows of seats in accordance with mathematical reckoning. The Greeks call them Echeia. The differences of the sounds which arise are combined into musical symphonies or concords: the circle of seats being divided into fourths and fifths and the octave.

Hence, if the delivery of the actor from the stage is adapted to these contrivances, when it reaches them, it becomes fuller, and reaches the audience with a richer and sweeter note.

Vitruvius, on Architecture, Book I, - on training of architects, Loeb

Vitruvius' understanding of acoustics is impressive. He was aware of an acoustical problem caused by the reflection of sound waves, namely that interference to the original source is created by reflections making the original less clearly audible or defined. Vitruvius named this reflection of sounds resonantia (which differs somewhat from our modern day meaning of the word resonance which implies a sound being bounced back and forth repeatedly at a specific pitch). Although such reflections were kept to a minimum by the very design of Roman and Greek theatres, the resonantia would still have been seen as a considerable problem. If any extraneous strong reflections come back to a listener at slightly different times, then speech, for example, would have become difficult to understand. As Vitruvius pointed out, an inflected language such as Latin is difficult to understand when the final syllables of words arrive at slightly different times. These theatres were outdoor venues often built into the side of a hill. The dryness of the resultant acoustic was also a problem for Vitruvius when dealing with music and he went to considerable effort to invent a system that would counteract it. Resonating bronze vases were his solution to this problem.

...let bronze vases be made, proportionate to the size of the theatre, and let them be so fashioned that, when touched, they may produce with one another the notes of the fourth, the fifth, and so on up to the double octave.

...the voice, uttered from the stage as from a centre, and spreading and striking against the cavities of the different vases, as it comes in contact with them, will be increased in clearness of sound, and will wake an harmonious note in unison with itself.

Vitruvius, The Ten Books on Architecture, Book $V$, Dover

How well did the vases work? It remains unclear. 


\subsection{Musical theory within the theatre}

Whilst there are no known original resonating vases in existence, a number of sites show evidence of spaces (niches) where the vases would have been positioned.

12 pairs of compartments corresponding to those described by Vitruvius have been found in the supporting wall of the uppermost row of seats of the Greek theatre at Aizani in Phrygia, eight in the podium of the Roman theatre at Nicopolis, and seven in the Greek theatre at Scythopolis in Syria. There are 20 niches in the upper part of the Greek theatre of Gerasa in Jordan; at Ierapetra and Gortyn in Crete the theatres have 13 niches each; and at Lyttos, also in Crete, there are three rows of 13 niches each.

Grove Dictionary (Belli, 1854, Müller, 1886).

Vitruvius states that different numbers of vases should be used depending on the size of the theatre.

The method of marking out the positions in which the jars are to be placed is as follows. If the theatre is not very large, a horizontal line should be marked out, halfway up the slope [of the auditorium], and 13 vaulted cubicles built, with 12 equal intervals between them: then the sounding jars as described above are placed in them.

So by this arrangement, the voice, radiating from the stage as from a centre, spreads itself around [the auditorium]: and, by exciting resonance in particular vases, produces an increased clarity and a series of notes which harmonize with itself.

Vitruvius, The Ten Books on Architecture, Book V, Dover

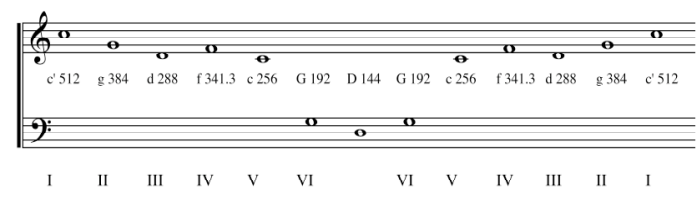

Figure 2 - vessel pitches for a small theatre

$\begin{array}{ll}\text { I } & \text { nëtë hyper bolaiön } \\ \text { II } & \text { nëtë die zeugmenon } \\ \text { III } & \text { paramese } \\ \text { IV } & \text { nëtë synhemmenön } \\ \text { V } & \text { mesë } \\ \text { VI } & \text { hypatë meson } \\ \text { in media } & \text { hypatë hypatön }\end{array}$

Fig. 2 shows the pitches (with Greek names) of the vases for a small theatre as specified by Vitruvius. Vase I (nëtë hyper bolaiön) would be placed at either side of the theatre with the in media vase (D 144) placed centrally. All others would be equidistant between.

Larger theatres required a greater number of vases arranged in three horizontal rows (one for the harmonia, a second for the chromatic and a third for the diatonic).



Figure 3 - vase pitches for a large theatre

Vitruvius discusses why acoustic vases were not used in the theatres of Rome. Owing to their wooden construction, singers who wished to increase the projection of their sound could direct their voices towards the scene doors (valvae). When a theatre is made of solid materials (such as stone) then it should be equipped with the vases as specified. Vitruvius states that there are many examples in Greek cities (Corinth). The expense of the bronze vases is also considered by Vitruvius:

Many clever architects who have built theatres in small cities, from the want of others have made use of earthen vases, yielding the proper tones, and have introduced them with considerable advantage.

Vitruvius, The Ten Books on Architecture, Book $V$, Dover

\subsection{How did the vases sound?}

It is likely that the function of the vases would have been to make some sounds louder than others by allowing them (or the air within them) to sympathetically vibrate when certain harmonics 'hit' them. So, when a singer 
performs a perfectly in-tune scale, a number of vases would ring creating a harmonic chord. An artificial reverberation (RT60 time estimated as $0 \cdot 2-0 \cdot 5$ seconds, Landels) containing only those harmonics listed in the vases pitches would be produced in an open-air theatre that would otherwise have none.

There may be another purpose for the vases other than those already mentioned. Some believe the acoustic jars helped singers and those relying on ear for maintaining pitch to keep to proper pitch. As indicated, the resonance of the vases would have given emphasis to important pitches leaving the others silent. If the artificial reverberation concept is difficult to accept, the assisted resonance idea is perhaps a little more attractive.

No definitive answer has been found to the question of authenticity and intent with regards Vitruvian resonating vases. It is known that many of the original bronze vases were later used for other purposes and even melted down. The earthenware vases are obviously more prone to damage making them more unlikely to survive the ravages of time.

We have only limited information as to how large and what shape they were and this information varies depending on which translation you use of the Vitruvian text. As a result, a lot of reasoning and occasional down right guesswork is required in order to begin piecing together the enigma of function and intent.

\section{VIRTUAL RECONSTRUCTIONS}

\subsection{Touching the vases...}

We can assume that the word 'touch' as used by Vitruvius means to make the vases (or the air inside them) ring sympathetically when the vibration of a sound source with a particular frequency in its harmonic series comes into contact.

\subsection{Additive synthesis method}

The author began designing software based upon the concepts of Vitruvius in 1999. Max/MSP was making real time synthesis on existing computers a practical possibility (a sixteen oscillator additive synthesiser taking up around $30 \%$ of the CPU of an Apple Macintosh G3 266 computer). The experiments began by building a synthesizer using the ratios specified by Vitruvius to explore the types of sound to be generated. A number of assumptions were made as to how the vases would have sounded - a principle assumption being that the harmonics would be largely sinusoidal.

No attempt was made at modelling the amplitude envelope of the vessel, although it would have been relatively simple to do. This proved to be a very enlightening way to proceed as it made the author address issues of authenticity in the modelling process. Clearly this was an artistic reconstruction based upon the Vitruvian principle where many of the physical constraints (decay time and other naturally occurring acoustic phenomena) could be largely ignored as a result of being in the digital domain. Experiments were carried out using ten, sixteen and thirty-eight oscillators. These numbers were based up the number of vases found in theatres depending on their size. In the early experiments, one oscillator was used to represent one vessel. Clearly, a great many more oscillators would be needed using the additive method if an accurate representation was to be made.

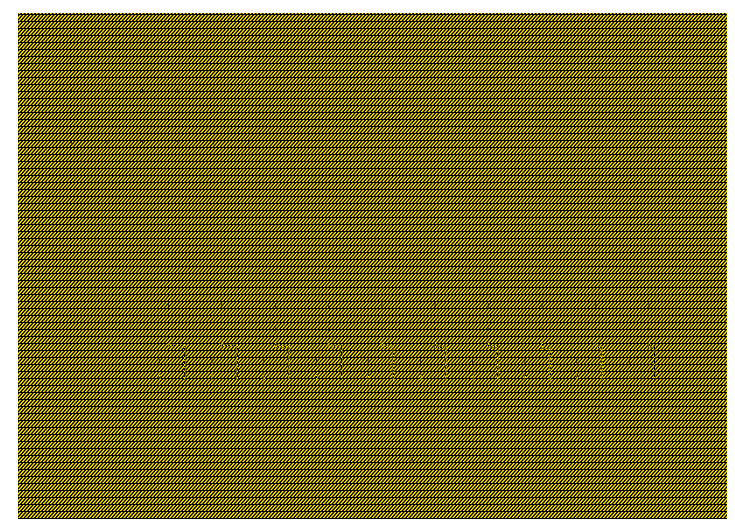

Figure 4

Fig. 4 shows an additive synthesis patch consisting of sixteen oscillators (ten shown here). The programme can be used to trigger the oscillators via external sound (using percussive or pitch detection objects, [bonk ] or [fiddle ] for example), which would be close to the original function of the Vitruvian vases. Video input via SoftVNS or Jitter, other sensor input or via a quasi-random process for automatically 'sounding' the oscillators are also possible. As we are in the digital domain, we are not dependant upon further physical constraints.

Ironically, what began as a simple experiment produced some very interesting 
musical results. The quasi-assisted resonance approach has featured in most of the author's work over the past six years.

\subsection{Impulse response method}

By clapping your hands in a church, you are listening to the church's response to the impulse your palms have made. Commercially available convolution reverberation software is available to emulate such responses. What this means is that it is possible to 'sample' an acoustic and use it as a plug-in of your choice. Audioease have developed Altiverb ${ }^{\mathrm{TM}}$, software that allows the user the opportunity of combining a dry input sound with an impulse response created in a real acoustic environment.

From conversations with Stephen Morris (Department of Physics, University of Toronto, Canada) at the Subtle Technologies Conference, Toronto, May 2005, we believe that the material of the vase itself is relatively unimportant. It is the air inside the vase that would resonate and not the physical material of the vase (Vitruvius does state that bronze or 'earthenware' options would work and also suggests that the use of different material is largely down to economic practicalities).

Ironically, a vase closely matching the patterns detailed by archaeologists and historians was found recently in a farm shop close to the author's home! A Greek farmer is importing a variety of vases from Crete and selling them as garden ornaments, water-features...

By spending some time singing into the vases, it soon became clear that these objects resonated quite effectively at certain frequencies, and that these frequencies could be changed by placing material (sand, water etc.) into the vase.

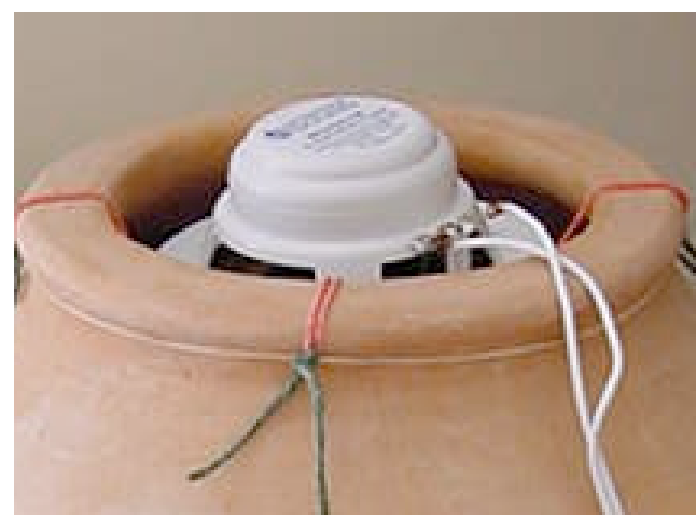



Figures 5 and 6

Figures 5 and 6 show modern earthenware vases (manufactured in Crete). Approximate dimension are $60 \mathrm{~cm}$ high with a neck $18 \mathrm{~cm}$ wide. The close-up of the neck shows a loudspeaker with a 5-inch driver suspended within the vase.

\section{ANALYSIS}

A variety of impulse responses were created using the Altiverb ${ }^{\mathrm{TM}}$ Impulse Response PreProcessor software. Sinusoidal sweeps gave the best results when a good quality loudspeaker was placed around $150 \mathrm{~cm}$ from the neck of the vase (not within it as the images indicate). The microphone used to record the sweep was also placed in a variety of positions - the most dramatic result being produced when placed several centimeters inside the neck of the vase.

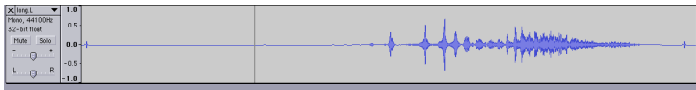

Figure 7

Fig. 7 shows a waveform of a recording of the impulse (sweep). A number of peaks can be seen. The frequencies of these peaks for this vase are as follows (the vase can be 'transposed' by changing its volume): 
It is likely that there will be many higher harmonics, but those shown gave an accurate rendition of the resonance of this vase. Interestingly, it is far from obvious what the fundamental of the vase is!

The impulse responses within Altiver $^{\mathrm{TM}}$ gave interesting results when different sounds were played through them. Speech gave strong resonant results (male voice). Some of the existing synthesized drones were also played back. Obviously, those that contained a high number of frequencies close to those listed above gave strong resonant results.

\subsection{Physical reconstructions}

Early in his career, Per Brüel attempted to duplicate the resonating vase concept by physically building a series of vases to experiment with. None of Vitruvius' original diagrams illustrating the size and shape of the bronze vases survive so Brüel's experimental vases were made of clay in a wine-beaker shape. Brüel claims his experiments showed that they enhanced reverberation at the resonant frequency (although the vases were not tested in a real theatre or in an anechoic chamber).

Ideally, a complete set of vases needs to be made. However, the sheer cost of a minimum of ten bronze vases has presumably prevented most researchers from pursuing the project. A combination of all available methods (physical and digital) may provide a truer picture that is realizable commercially, scientifically and artistically.

\section{THE CONCEPT AS COMPOSITION}

\subsection{Halo for piano and responsive electronics}

Receiving its US premiere at the ICMC, New Orleans, 2006, Halo uses an additive synthesiser to emulate the Vitruvian resonances, triggered by a microphone detecting transient dynamic changes ([bonk ]). Halo was recorded by Philip Mead and the author for the UH Record Label.

\section{2 inside the eye of silence}

\section{- a collaboration with Vivienne Spiteri}

The following is a programme note by Vivienne Spiteri for inside the eye of silence. It demonstrates their preoccupation with the Vitruvian concept and how they pushed the principle away from a purely practical 'problemsolving' idea.

where does sound stop and silence begin, end, sound, begin?

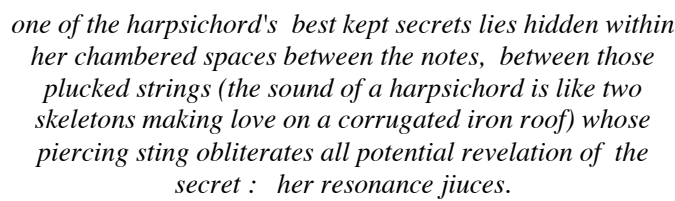

to isolate a single sound, to let the time-life of a solitary plucked string linger, live and rise through to its natural end, is to reveal all: birth, breath, life, death and rebirth. all swell with song. skeletons no more this full-bodied dancing sound, laughing and rejoicing, these rich spectra liberated, escaped from their string prison, these wingéd frequencies, free as air.

$$
\begin{gathered}
\text { air } \\
\text { ah, air } \\
\text { space } \\
\text { air-space } \\
\text { and time }
\end{gathered}
$$

where do air, space and time unite?

"and time is te space your mind movs through" (gwendolyn macewen:

"vacuum genesis" from afterworlds 1987-88)

sound. sound becoming silence through air-travel, through open air, through air within a space. an enclosed space? of time? time, ah time. sound's phantom vessel. where does it wander? what is its voyage? what is its voyage, never lowering anchor?

to step inside the eye of silence is to listen deeply, to feel it at your ear. for as long as air and time give it wing, sound-insilence-in-sound births and breathes itself, expanding, contracting, like the lungs of a whale, huge and light as air.

enter vitruvius, ah vitruvius. he who knew the secret of the wingéd. his siren-song, embodied in resonating bronze inside semi-circular spaces of another place, an other time, drew forth, beguiled and captured the wild and wandering waves, colouring them lively: live, alive, life. long life. longer still. unending

enter the spider, weaver of webs, silent siren temptress, vitruvius-collaborator inside the eye, along her radii.

toronto. chemistry building. hanlan's point. harpsichord as siren temptress inside the eye, weaving through space, resonanting her chambers.

listen, dive, fly, let the air wing you
around
space
is time
is sound is
silence
is

infnity's music

(C) Vivienne Spiteri August 2002 


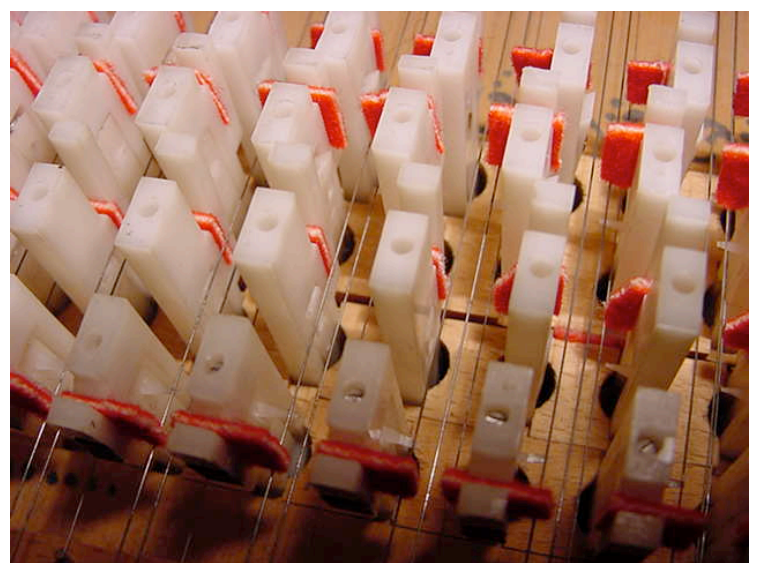

Figure 8 - image from the documentary DVD version of inside the eye of silence.

Commissioned by New Adventures in Sound Art for Sign-Waves, inside the eye of silence used granular synthesis to mimic Vitruvian resonances. It was first shown in a multi-room environment using an octaphonic system at The Chemistry Building, Toronto Island, Canada in August 2002.

\section{CONCLUSIONS}

We should at some point be brave enough to ask (and potentially answer) a simple question - did the vases as specified by Vitruvius actually do their intended job? There is now a significant amount of evidence to support the concept. Other resonating vases have been found throughout history and some are still in use. There is no doubt that Vitruvius was the source for vases used in medieval churches. In Europe there are examples found in St. Clements, Sandwich, Kent; St. Peter Mancroft, Norwich; Fountains Abbey, York; and St. Martin, Angers, Bjeresjoe, Sweden. Most of these jars are between $20 \mathrm{~cm}$ and $30 \mathrm{~cm}$ in length with fundamental frequencies of between 90 to 350 $\mathrm{Hz}$ (not far away from the pitches specified by Vitruvius). However, some of these examples of vases used in churches may have been used to reduce reverberation and echoes by absorbing resonance. Many were cemented into place and not freely placed as with the Vitruvian examples. This would greatly reduce their efficiency as resonators. So, with these many contradictions, it is hardly surprising that archaeologists are wary of the function of vases.

\section{BIBLIOGRAPHY}

-Vitruvius. The Ten Books on Architecture, Loeb 1960, Dover 1960 and Cambridge University Press 2002

-Grove, Dictionary of Music (various) 1998

-Landels, John G. Assisted Resonance in Ancient Theatres - Greece \& Rome XIV, Routledge 1967

-Landels, John G. Music in Ancient Greece and Rome, Routledge 2000

-Robert G. Jahn, Paul Devereux, and Michael Ibison, Acoustic Resonances of Assorted Ancient Structures (J. Acoust. Soc. Am. 99(2): 649-658. February 1996)

-Harrison, Kenneth. Vitruvius and Acoustic Jars in England during the Middle Ages, Ancient Monuments Society 1967-68

-Levin, F. R. The Manual of Harmonics of Nicomachus the Pythagorean (translation), Phanes 1994

-James, J. The Music of the Spheres, Abacus, 1993

-Roads, Curtis, The Computer Music Tutorial (for Granular Synthesis, 168-184), MIT 2001

\section{WEBLIOGRAPHY}

http://www.herts.ac.uk/artdes1/research/papers/wpade s/vol4/rgfull.html http://www.thedark.net http://www.soundtravels.ca http://www.digitaljourney.org.uk http://www.philophony.com/pages http://www.audioease.com

\section{ACKNOWLEDGEMENTS AND ADDITIONAL REFERENCES}

I am very grateful to Stephen Morris (University of Toronto) and Lydia Sharman (Concordia) for inspiring me to pursue the physical characteristics of these vases.

I would also like to thank Per Briiel for discussions in-person at the First PanAmerican/Iberian Meeting on Acoustics in Cancun, Mexico, 2002; Aaron Watson for equally illuminating conversations at Reading University 2002 and private communication with John Landels and Sam Moorhead (British Museum). 